\title{
Integration of gamification in a traffic education platform for children
}

\author{
Riaz, Malik Sarmad; Cuenen, Ariane; Janssens, Davy; Brijs, Kris and Wets, Geert \\ Transportation Research Institute (IMOB), Hasselt University, Belgium
}

\begin{abstract}
Children are highly represented in injuries and fatalities caused by road accidents. The major reasons are children's lack of ability to scan the environment, inconsistent behavior, distraction in traffic situations, ability to estimate speed and distance, and less developed hazard perception skills. Therefore, traffic education for children is very important. This study will look at a platform about traffic education for children including gamification elements. Gamification is a relatively new concept which has gathered a lot of attention over the last few years with its application in many diverse fields. Gamification is defined as the application of game mechanics to non-game activities in order to change behavior. The education community has discovered the power it has to increase students' performance and engagement. The current study focuses on educating school going children on traffic safety in Flanders (Belgium). We expect the platform to be effective in increasing traffic knowledge, situation awareness, risk detection and risk management among children and a positive change in (predictors of) behaviors of children who will be using the platform. To investigate the effect of the platform, a pretest-posttest design with an intervention group and acontrol group will be used. Data will be collected and analyzed in the spring of 2018 and results, limitations and policy recommendations will be provided during the conference in June 2018.
\end{abstract}

Keywords: E-learning; Gamification; traffic; education; children. 


\section{Introduction}

Road traffic accidents have been described as the leading cause of death among 0-19 year olds by the World Health Organization (WHO, 2014). In Europe, road traffic accidents still account for 1 in 5 fatalities (WHO, 2004). School going children have the highest injury rates if adjusted for miles ridden. The major reasons are children's lack of ability to scan the environment, inconsistent behavior, distraction in traffic situations, ability to estimate speed and distance, and less developed hazard perception skills (Connely, Conaglon, Parsonson, and Isler, 1998; Scialfa et al., 2012). Most of these accidents happen at intersections and crossings (Scialfa et al., 2012).

The three types of factors that can lead to a road traffic accident are human factors, environmental factors and vehicle factors according to the Haddon matrix. The research conducted by Treat, Tumbas, and McDonald (1977) found out from the crash data that human factors (i.e., error or lack of judgement) can contribute to $95.4 \%$ road traffic accidents. These human factors can involve not having the right skills to cross a road or wrong attitude to traffic laws. There are three interventions to improve road user safety which are known as the 3 E's of traffic safety: Engineering, Enforcement and Education. Engineering aims to improve the existing transportation infrastructure. Enforcement, on the other hand, is related to the monitoring of violations like speeding, distracted driving, and impaired driving. Education involves making each individual familiar with traffic rules and motivate them to follow these rules as breaking these may results in an increased chance of crash. Traffic education is important for all road users as all the participants of the road are equally responsible for traffic safety. Therefore, the present study will focus on traffic education. Applying the rules of the road, searching for potential hazards, remembering where they are, reacting quickly to emergency situations and choosing safe gaps to cross or turn can decrease the number of accidents children are involved in as pedestrian and cyclist.

\subsection{Traffic Education}

Traffic education for children is vitally important to help children understand the traffic rules, and improve their attitude towards road safety, as it gives them a great chance of keeping safe while they are young. Ben-Bassat and Avnieli (2016) have shown that there is a positive impact of traffic education on children's behavior and attitudes. There have been many bicycle safety programs, as bicycling involves the use of both motor skills and scanning the environment for threats (Ducheyne, De Bourdeaudhuij, Lenoir, \& Cardon, 2014; Lachapelle, Noland, \& Von Hagen, 2013; McLaughlin \& Glang, 2010; Zeuwts, Vansteenkiste, Cardon,

\& Lenoir, 2016) There is a lot of literature on children hazard perception evaluation and training with children as pedestrians (Meir, Oron-Gilad, and Parmet, 2015; Rosenbloom, 
Mandel, Rosner, and Eldror, 2015) and cyclists (Lehtonen, Havia, Kovanen, Leminen, and Saure 2016; Vansteenkiste, Zeuwts, Cardon, and Lenoir 2016).

Our study differs in the approach that it would be a course on traffic safety covering several aspects of traffic education by using an e-learning platform while the studies mentioned above were either conducted on solely hazard perception (risk detection) for pedestrians and cyclists for a limited time or on site for bicycle skills evaluation and training. To our knowledge, this platform is the first platform which makes use of context relevant footage for the traffic education training. The first half of the training will include pictures from the children's own city followed by the pictures and movies from other towns in Belgium, to see how they react to familiar and unfamiliar traffic situations. Extending what has been learned in familiar situations can help in reacting safely to a traffic situation in a different location. This would also help us in recognizing any transfer effects using context relevant data. In addition, the platform also differs in the approach compared to other studies since it uses embedded gamification elements.

\subsection{Gamification}

There are many definitions available on gamification. Werbach and Hunter (2012) define gamification as "embedding game features into activities which are not games themselves". The concept of gamification in education is not new, with students awarded with badges for performing well in classes. Now with the advent of technology, it is being used in elearning, and has been providing favorable results regarding better academic outcomes and engagement (Çakıroğlu, Başıbüyük, Güler, Atabay, \& Yılmaz Memiş, 2017). Gamification works as it focuses on reinforcements. Reinforcements encourage repetition of the behavior (Skinner, 1938). The reinforcements can be extrinsic or intrinsic. In the education domain, the rewards can be prizes/money (extrinsic) or enjoyment/fun (intrinsic). As Skinner (1938) has mentioned that only those behaviors are repeated which have satisfying outcomes. Gamification focuses on the repetition of the desired outcomes, so the required behavior becomes a habit.

Sailer, Hense, Mayr, and Mandl (2017) have discussed the game elements and their effect on psychological needs. Some of the gamification elements that can be applied in any elearning platform are points, badges, leaderboards, performance graphs, avatars and groups. The need for competence is fulfilled by points, badges, leaderboards and performance graphs. Choosing avatars can give the students a sense of autonomy and what they want to do next, while doing tasks together in groups can have a sense of social relatedness (Sailer et al.,

2017). Krause, Mogalle, Pohl, and Williams (2015) have shown that adding gamification elements like points and progress bars increased retention of students and performance in an e-learning platform. Facey-shaw, Borner, Specht, and Bryan (2015) described the 
positive effect of digital badges being incorporated in an e-learning platform with increased user engagement and performance.

\section{Traffic Education Platform}

The present study will be conducted on pupils of primary school in Flanders (Belgium). The goal of this study is to increase knowledge, situation awareness, risk detection and risk management among users of the platform. For the current study, gamification elements like points (granular feedback), performance graphs (sustained feedback), and badges are incorporated. We expect that these gamification elements increase students retention, and enhance the experience which will help reach the targets set out in the project.

\subsection{Methodology}

After looking at literature in the field of traffic education, the platform was developed in four major modules: knowledge, situation awareness, risk detection and risk management. These four modules cover most of the issues with children in traffic. In the knowledge module, attention is given to what they need to know about traffic laws. In the situation awareness, attention is given to awareness of the traffic situation. Risk detection and risk management deal with hazard perception of the children by paying attention to thedetection of hazards (risk detection) and then responding to that threat (risk management). After the user selects the response, it is followed by a detailed feedback for each question.

Footage for the platform was collected by capturing pictures and videos of traffic situations. A camera was mounted on the handlebar of the bicycle to have pictures and videos from a bicyclist perspective. The pictures and videos were further divided in categories based on the modules described above (i.e., knowledge, situation awareness, risk detection and risk management), and also based on context relevant data with familiar and unfamiliar traffic situations.

\subsection{Participants}

The study will be conducted among pupils of primary school in Flanders (Belgium). The intervention group and the control group, both consist of 70 pupils.

\subsection{Study design and analysis}

The study is a pretest-posttest design with an intervention group and a control group to check the effectiveness of the training program. A pre and post questionnaire will be filled by the participants before and after completion of the training. The questionnaire will involve demographic info, along with questions related to predictors of behavior from the theory of planned behavior. A process evaluation questionnaire will also be administered at 
the end of the training for checking the overall satisfaction with the training, and the effect of gamification elements on learning. Data will be collected and analyzed with SPSS in the spring of 2018.

\section{Results}

The results of both the effect evaluation and process evaluation will be presented. Some of the results on the effect evaluation will provide us with the following results:

a. Which traffic rules or laws are difficult to comprehend for children?

b. Which traffic situations are difficult for children to comprehend?

c. What sort of hazards are difficult for children to detect?

d. What sort of hazards are difficult for children to manage?

e. Effect on knowledge, situation awareness, risk detection and risk management?

f. Effect on predictors of behavior i.e. intention, attitude, perceived behavioral control and subjective norm of participants towards traffic safety behavior?

We will also present the results of the process evaluation: users opinion about the platform and overall satisfaction with the platform, and which gamification elements were helpful in increasing children's engagement with the platform.

\section{Discussion}

After the study is conducted, the results, limitations and policy recommendations will be discussed. One recommendation could be that if results are positive, it would be important to investigate long-term effects of such an intervention and see if there is a necessity to have booster sessions periodically to reinforce the progress made by the intervention.

\section{References}

Ben-Bassat, T., \& Avnieli, S. (2016). The effect of a road safety educational program for kindergarten children on their parents' behavior and knowledge. Accid Anal Prev, 95(Pt A), 78-85. doi:10.1016/j.aap.2016.06.024

Çakıroğlu, Ü., Başıbüyük, B., Güler, M., Atabay, M., \& Yılmaz Memiş, B. (2017). Gamifying an ICT course: Influences on engagement and academic performance. Computers in Human Behavior, 69, 98-107. doi:10.1016/j.chb.2016.12.018 
Connelly M.L, Conaglen H.M, Barry S. Parsonson, \& Isler, R. B. (1998). CHILD PEDESTRIANS' CROSSING GAP THRESHOLDS. Accident Analysis and Prevention, 30(4), 443-453.

Ducheyne, F., De Bourdeaudhuij, I., Lenoir, M., \& Cardon, G. (2014). Effects of a cycle training course on children's cycling skills and levels of cycling to school. Accid Anal Prev, 67, 49-60. doi:10.1016/j.aap.2014.01.023

Krause, M., Mogalle, M., Pohl, H., \& Williams, J. J. (2015). A Playful Game Changer. 95 102. doi:10.1145/2724660.2724665

Lachapelle, U., Noland, R. B., \& Von Hagen, L. A. (2013). Teaching children about bicycle safety: an evaluation of the New Jersey Bike School program. Accid Anal Prev, 52, $237-$ 249. doi:10.1016/j.aap.2012.09.015

Lehtonen, E., Havia, V., Kovanen, A., Leminen, M., \& Saure, E. (2016). Evaluating bicyclists' risk perception using video clips: Comparison of frequent and infrequent city cyclists. Transportation Research Part F: Traffic Psychology and Behaviour, 41, 195203. doi:10.1016/j.trf.2015.04.006

Lisa Facey-Shaw, Dirk Börner, Specht, M., \& Bartley-Bryan, J. (2015). A Moodle-based Badge System for Evaluating the Motivational Levels of Introductory Programmers.

Marie L. Connelly, Helen M. Conaglen, Barry S. Parsonson, \& Isler, R. B. (1998). CHILD PEDESTRIANS' CROSSING GAP THRESHOLDS. Accident Analysis and Prevention, 30(4), 443-453.

McLaughlin, K. A., \& Glang, A. (2010). The effectiveness of a bicycle safety program for improving safety-related knowledge and behavior in young elementary students. $J$ Pediatr Psychol, 35(4), 343-353. doi:10.1093/jpepsy/jsp076

Meir, A., Oron-Gilad, T., \& Parmet, Y. (2015). Can child-pedestrians' hazard perception skills be enhanced? Accid Anal Prev, 83, 101-110. doi:10.1016/j.aap.2015.07.006

Rosenbloom, T., Mandel, R., Rosner, Y., \& Eldror, E. (2015). Hazard perception test for pedestrians. Accid Anal Prev, 79, 160-169. doi:10.1016/j.aap.2015.03.019

Sailer, M., Hense, J. U., Mayr, S. K., \& Mandl, H. (2017). How gamification motivates: An experimental study of the effects of specific game design elements on psychological need satisfaction. Computers in Human Behavior, 69, 371-380. doi:10.1016/j.chb.2016.12.033

Scialfa, C. T., Borkenhagen, D., Lyon, J., Deschenes, M., Horswill, M., \& Wetton, M. (2012). The effects of driving experience on responses to a static hazard perception test. Accid Anal Prev, 45, 547-553. doi:10.1016/j.aap.2011.09.005

Skinner, B. F. (1938). The Behavior of Organisms An Experimental Analysis: New York : Appleton - Century.

Treat, J. R., Tumbas, N. S., \& McDonald, S. T. (1977). Tri-level study of the causes of traffic accidents. Retrieved from Institute for Research in Public Safety. :

Vansteenkiste, P., Zeuwts, L., Cardon, G., \& Lenoir, M. (2016). A hazard-perception test for cycling children: An exploratory study. Transportation Research Part F: Traffic Psychology and Behaviour, 41, 182-194. doi:10.1016/j.trf.2016.05.001

Werbach, K., \& Hunter, D. (2012). For the win: How game thinking can revolutionize your business.: Wharton Digital Press. 
WHO. (2004). World report on road traffic injury prevention. Retrieved from http://www.who.int/violence injury_prevention/publications/road traffic/world report/ $\underline{\text { en/ }}$

WHO. (2014). Children and road traffic injuries. Retrieved from http://www.who.int/violence_injury_prevention/child/en/

Zeuwts, L., Vansteenkiste, P., Cardon, G., \& Lenoir, M. (2016). Development of cycling skills in 7- to 12-year-old children. Traffic Inj Prev, 17(7), 736-742. doi:10.1080/15389588.2016.1143553 